\title{
Proper OBJECTS AMONG OTHER THINGS
}

\author{
Jette Sandahl
}

Objects are imagined, envisioned, fantasized, talked about - seen sometimes as mental shapes and constructs long before they find material expression.

Objects come into being through century-long traditions and continuity, through foresight, labour and care or are created from seemingly divine inspiration.

Most objects are made out of necessity. Some are just for fun.

Objects are made for trade, for money, some are made only for love.

They are bought and sold, exchanged, bartered, given away.

They are used, consumed, kept and thrown away.

Some are kept, although no longer useful.

Objects fill needs.

Objects are projections of our needs and desires.

They are material externalizations of our needs and desires.

They tie together the material and the immaterial world".

Producing objects to facilitate the scratching of a living on the surface of the earth is said to be a basic human characteristic. Objectifying ourselves in the material world is thought to be the human 'project' as such.

However essential or inherent, this objectification always takes place within a given social and historical setting that assigns a specific meaning to the relationship between the subject and object. Will they stay together till death does them part, remain united, or were they always meant to part and will happily do so? Will they turn against each other in hostility or contempt or will they be forcibly divorced? Will the object leave the creator alienated or as a commodity turn against the creator as reification?

Objects link people. The care and energy or soul poured into an object is returned through other objects, other people's objects. In our world the chains of objects linking people become longer, more complex, more far-reaching. They span the globe now. 
98 People can turn each other into objects - and back into subjects or leave each other dangling like things.

Objects have genders. Some languages assign several genders to objects. Some only one.

Museums beg objects to turn into subjects. We try to make them speak, to read them, or their memories, what they have transmitted, facilitated, prevented, what they have experienced or only witnessed. We coach them into revealing the story of their lives.

Some of these stories sound as old as light years.

Some of the lives are long, span several generations of our own. Some objects have seen death and been resurrected. Some have risen as new beings with a new well-defined purpose in life. Some keep metamorphosing in ever humbler, but still functional and useful shapes. All seem to be in the grip of age. For most of those in our possession we are their last station in life. When they enter our gates, we promise to bestow on them eternal life.

Here is a list of objects that I sincerely wish would talk to me:

- the fifty odd different kinds of grains found in the stomach of the Grauballe man to tell me about the relative importance of gatherers and hunters, and of women's status in the transition towards cultivation of the land

- the glass beads that Jürgensen Thomsen says we also used to love when we were savages and such treasures were bought to us by civilized nations, because then I might ask them about the rise and fall of civilizations and nations

- painted stick, can-of-beans and conch shell of Tom Robbins novel 'skinny legs and all' as three objects which get their molecules steaming and each according to his/her/its gender take part in the spiritual and sexual rituals of our times and might teach us more of the androgynous

- the lions that Alice Walker says used to wander freely in and out of the palace of Ethiopia as late as in the era of Heeili Selassi, so that I might get different news of the lion goddess Sakhmet than that she symbolizes the sun when it is as dangerous as a lion. Might it be that she is also potent, powerful, protective, stoic, generous, benevolent, friendly - and also always potentially dangerous?

- as many female deities as our building will hold until museums feel obliged to deal with why, how and when they disappeared and what forms of societal organisations disappeared with them to ask if it is true that the worship of the great mother corresponds with no wars and cities that are not walled

- a lifetime of one woman's underpants to trace the brown stains of blood appearing, reappearing and disappearing as Raskin says in 'Hot Flashes'

- a Husquarna sewing machine to relate to me from the inside the connections and the differences in male and female cultures of work and production and use

- a bed in whose springs squeaks the small talk, the laughter, the sighs, the whinnying, the hard breathing of conception, birth and death

- the plough and the harrow used by Anna Thomsen, so that everyone would know that sexual divisions of labour in agrarian society are rarely exclusive and are not expected to have psychological correlatives 
- 9 premature ejaculations from men who were sure they were in firm control and full self-command, immediately followed by - 9 broken condoms, an equal number of broken hearts and broken promises, not necessarily related or of the same sex to always remind me 1 . to distrust technology and 2. to always keep in mind that pain and suffering spare neither gender

As museums we work with objects full of feelings, objects embodying human emotions. Museums animate them further, fill them, inspire them with meaning.

The objects are materialized emotions and emotional material.

In psychoanalytic theory a subject makes other people an object for her or his feelings, makes them objects for love and passion, obsesses them with feelings. Objects also become carriers of these obsessions - as when the child cathexes its teddy bear and tries to master the always redundant love for its parents through this transitional object.

As the relationships of property can leave the creator alienated relative to his or her own product, similarly the object of one's love or obsession can tear itself away and take on a life of its own. It can become a fetish. Most often there is this element of fetishism around our objects, in private as well as in museum collections.

It is, however, not so much the perversions, where the power of the objects have got out of hand that interest me. It is rather the middle ground, the in-between, the normality of objects and the objects of normality.

It is the process by which one internalizes the outside world, absorbs and assimi-
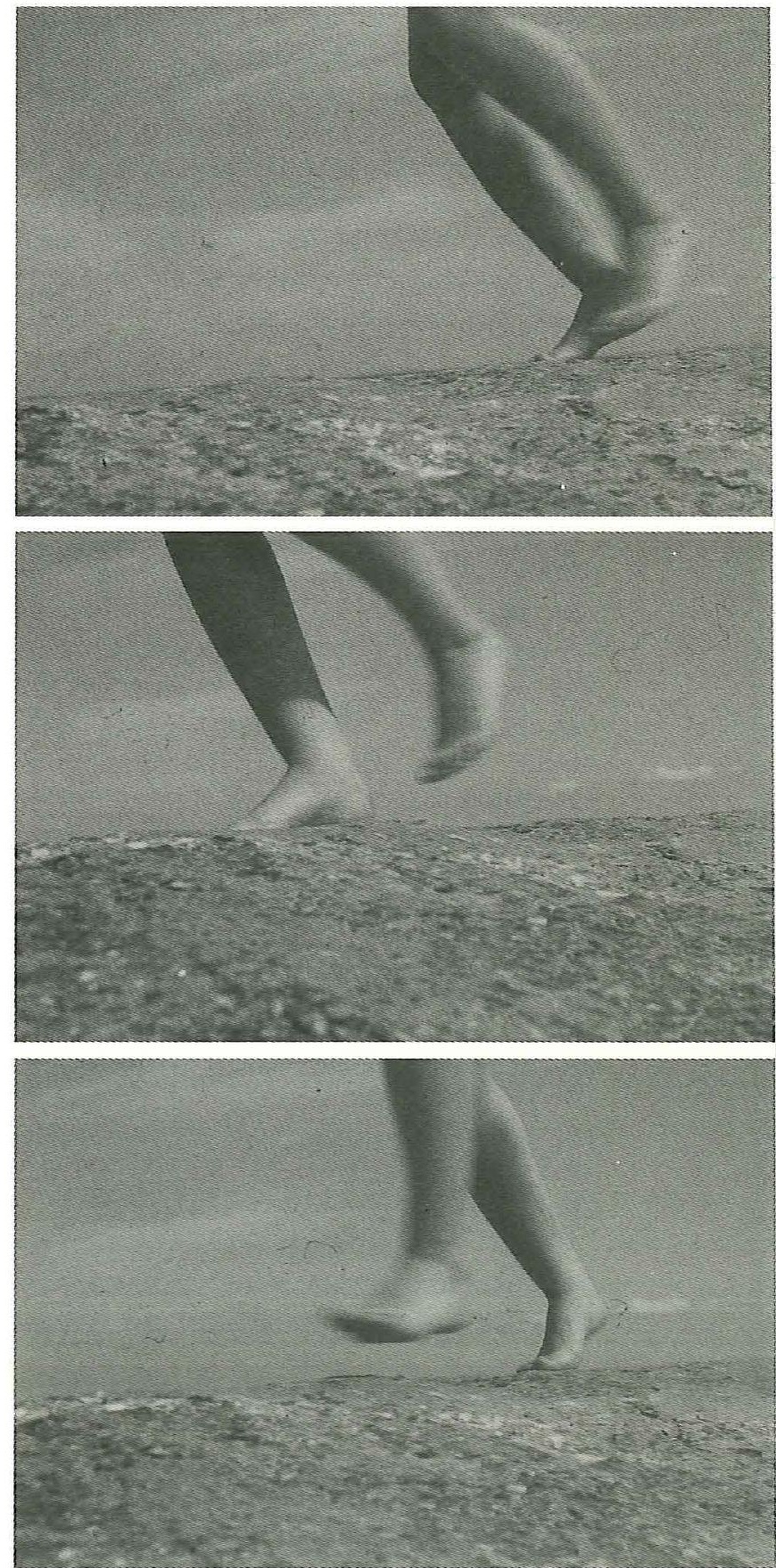
100 lates it, makes it part of oneself the same way as one externalizes oneself in the objects. It is the process in which people create the world in their image.

The inspired or obsessed objects in museum collections span teddy bears and thimbles, steam engines and bones, bats and butterflies. They span things so awful that I will not mention them.

The rise of museums mirrors closely the positive and negative obsessions that carry and delineate the identity of their time and their area.

The identity of museums mirrors closely different specific types of animations and obsessions.

Museums deal with objects as such, with the marks and traces embodied in the objects as such. We deal with the tangible things. They are the unique quality of museums, and our chance to balance between the material and the immaterial world and keep ourselves aware of their unity. The objects always remind us that we cannot discuss mind and spirituality without also dealing with sofas, grain and gravy.

But while the unknown, the unspoilt, the not yet researched or explored objects in our collections intrigue us, an object also grows in profundity and fascination the more knowledge we acquire about it.

Often it is through the surroundings, through the contexts, the relationships of the object, that its meanings and functions really become clear.

\section{Memories stick to objects.}

If we ask for the concrete, specific provenance of the object more than the general, we may find the object's symbolic position in the life of a woman, and follow and trace through the object the economic, social and emotional patterns and contexts in her life.

'I was standing right by this stove, when I told him I'd got myself pregnant', and the stove is the condensed symbol of her apprehension and her difficult, much too distant relationship to this man.

Or a woman steps into a certain summer's love affair whenever she puts on a certain pair of sandals. She remembers the wind on her thighs when the motorbike picked up speed, hears the sound of the sea and the feeling of travelling on, of travelling becoming almost a way of life. The shoes are no longer mere things, but contain very detailed memories and imagery. In the self-image of this woman they have become metaphors for her youth, when love, erotic generosity and the fluent lifestyle were basic elements of her identity.

Through the many different stories the common, shared or typical metaphors emerge. Mother love, for instance, showing up in the little name tags sown onto children's clothes before they leave for school or camp, each diminutive label or stitch containing the reluctance of separation mixed with the pride of seeing the child thrive, grow and ready to go. ${ }^{2}$

\section{Objects tie up strings of people.}

We have a collection of about 1500 items from five sisters, in which the maker and the owner of individual objects are very hard to determine. Ownership keeps shifting. Or an object was made by one sister and remade for a new function by another. The objects and their exchanges document the intense, lifelong community and involvement between the sisters, 
the extended family arrangements, the pleasure of making and giving gifts, the shared Christmasses, birthdays, Sunday trips and deaths over an 80-year period.

A collection of similar size and scope is centred in a villa, housing several successive generations of one family.

The objects here bear witness to the care put into preserving things in previous periods, even among the affluent. The objects keep outliving the people. Cups and saucers are riveted, stockings and nightgowns are darned and patched, and as such bear witness to a different culture where waste is shameful.

The downward mobility, but also the talent for survival, especially of textiles, when they go from gowns to rags, is certainly manifest in this collection.

Centred on the house ${ }^{3}$, this collection also shows the patterns of women's physical movements. Closets, linen baskets, washing machines and plans of the house show how, for instance, servants, wives and daughters had to take dirty laundry from the bedrooms on the 2 nd floor to be washed in the basement then taken to the 3rd floor loft to dry, then back into the basement to be ironed and back to the 2nd floor to be put away.

Shoes, dresses, bills, tickets, programmes and seating plans show the patterns of women crossing the threshold between the home and the public sphere. The washerwoman, the mender of clothes and the occasional cook came to the house, while members of the family went to the butcher's shop, to the real dressmaker's in her apartment, they went to school, went out for piano lessons, for the concerts and matinees and dinners that their social position entitled them to attend.
Of around 600 photos from this collection 2 or 3 include servants.

Bills for bread and milk show the price of daily products relative to wages, relative to the brass door handles installed, and relative to the costs of a male dinner party held.

The comings and goings within the collection compose a city map of class and gender. And it keeps raising the question of what is work for a woman?

These objects might speak for themselves, as we say, had we not also interviewed two generations of women on the family truths and myths.

In our homes all of us own things of a symbolic value that has often lost all connection with the original function. The objects as well as the emotions around them may be inherited from previous generations, or we may have cathexed them in our own lives and contexts.

A certain divorce party in New York became world famous for the intense happening of the couple splitting their marriage bed down the middle with a power saw. But also the less spectacular scuffles over division of property cry to heaven of hurt and violated memories and feelings rather than of material needs and financial worries.

The extent to which we remember and feel through objects, the extent to which objects are carriers of and media for our emotions, each of us comes to realize when we pack up and clear out the belongings of our dead ones - or when we obstinately refuse to do so when others find it proper. 
JETTE SANDAHL

102 Hairs and smells keep emerging after those that left or abandoned us - and they brutally activate memories. So do the scissors with which he used to trim his eyebrows, or the fountain pen with which he wrote his love letters. These objects stir memories behind or beyond the psychic level on which we meet for instance photographs with steeled reflexes and wellrehearsed lines of defence.

Objects may carry knowledge and recollection of otherwise forgotten or repressed feelings. One woman did not remember giving birth to her daughter who was born during World War II, but related in great detail how - heavily pregnant and after hours standing in a queue outside the department store - she managed to acquire the most lovely yellow wool for the baby's jersey, and how the daughter throughout many years as a junkie has kept and cherished this particular baby garment. Sometimes objects contain these cover memories, images superimposed upon other images, that are too painful to recollect.

Objects 'work' in museums because they 'work' in real life, they carry and signify meaning - and relationships. Objects become symbols or metaphors for specific activities, epochs, situations, relationships in people's real lives, and as such they 'recognize' objects in museums.

Objects elicit psychological reactions. People interact with things. They enter dialogues with the object, seeing it as 'similar', comparing it, contrasting it to what is known, to the echo the object arouses in their memories.

Objects dig deeply. Spontaneously they elicit memories and stored images that are not easily reached by other means, other languages. Objects - and the old tactile and olfactory senses to which they relate reach more deeply than the spoken language. Language does not in itself carry the memory or the emotion. Words name or describe the emotions, but are always one step further removed, one step more abstract.

Similarly, the images stored in objects stay fresh and retain their flavour. They give access to a very concrete and specific history that differs from the generalities that each of us have been taught to remember and believe of a given epoch. The objects of everyday life have remained relatively unaffected by clichées and established truths.

Objects speak the language of primary processes. They are analoguous. Like dreams they do not know the word 'not'. Objects say 'also' rather than 'not'. Like dreams they heap images on top of each other. They say 'both/and'. These multitudes of images may contradict each other and the sum total may be paradoxical. But objects do not carry negation. They speak literally, positively.

My museum is entrusted with many 'improper' objects. Objects that are not part of the 'official' identity, either of the individual or of society in general.

They are the personal stories of beatings, humiliations and back street abortions. They are the shameful or private objects. The humble things of poverty. The intimate ones of the bodies that are much too alive and bloody and vulgar for our society. There is the bridal dress that was never worn, because the groom took off, while the bride saved the dress and the dream throughout a lifetime of loneliness. 
Women have an especially acute and precise awareness of these objects as expressions of the shadow self, of the unconscious, of what is suppressed.

Museum exhibitions are imaginary worlds, in which individual elements and sometimes their contexts and groupings are original, authentic. But nonetheless, they are re-created worlds, that differ from the ones they re-present. Exhibitions are new contexts, new realities that should never be confused with the ones to which they refer. Exhibitions have their own rules and regulations.

In exhibitions the audience enters a dialogue with museum objects. More so with the three-dimensional things than with the pictures, texts and stories. Threedimensional objects seem more open to projection, to interpretation, to recognition and parables. They seem indefinite, even when their own specific history is presented.

In my exhibitions I like it when the audience talks. Chatters. When they gossip and try to tell the attendant or the guide everything. When they interpret.

If they do not talk, the displays are not working.

Different styles appeal to different types of people. Temporary exhibitions let us move freely between styles and types of exhibition languages, from intimate or monumental reconstructions to highly stylized, abstract designs, from shameless use of copies to a strict adherence to original objects only. It all depends.

It depends on the subject. It depends on the time. It depends on the audience you want to reach around precisely this theme.
While the dismantling of one's tempora103 ry exhibitions is often felt as a surprising loss, the advantage of the ever changing exhibitions is that they give us the freedom to play with the many different truths, the many different versions of our past and future. They do not bind us to the one truth, the one unequivocal interpretation of history that I have yet to see a permanent exhibition avoid or avoid confirming.

I always tend to believe that history might have turned out differently, and have spoken before of my desire to present exhibitions about the things that did not happen as a way of making the choices in history stand out.

Enlightened intuition is what we sometimes call the process behind an exhibition design. It is an art form that needs a basis of precise knowledge of its subject matter to work. Or it is a body of knowledge that needs an artistic intuition to become other than a book on the wall or objects on shelves or silver plates. The designer has to be at home in her/his historical material for her/his own subjective symbolisms and metaphors to coincide with and to touch other people's imaginations. Again, the concrete has to reverberate through the general and typical.

In my experience the narrative is important. The narrative can be there as a simple chronology, chronology of age or time lines of displays, it can be stories, in texts or sound or pictures, or it can have the more dramatic form of individual portraits or drama. The narrative can be a leitmotif of pattern or sequences of patterns, in the objects or in the design.

One feels the need to invent a narrative, if the exhibition fails to give it. 
JETTE SANDAHL

104
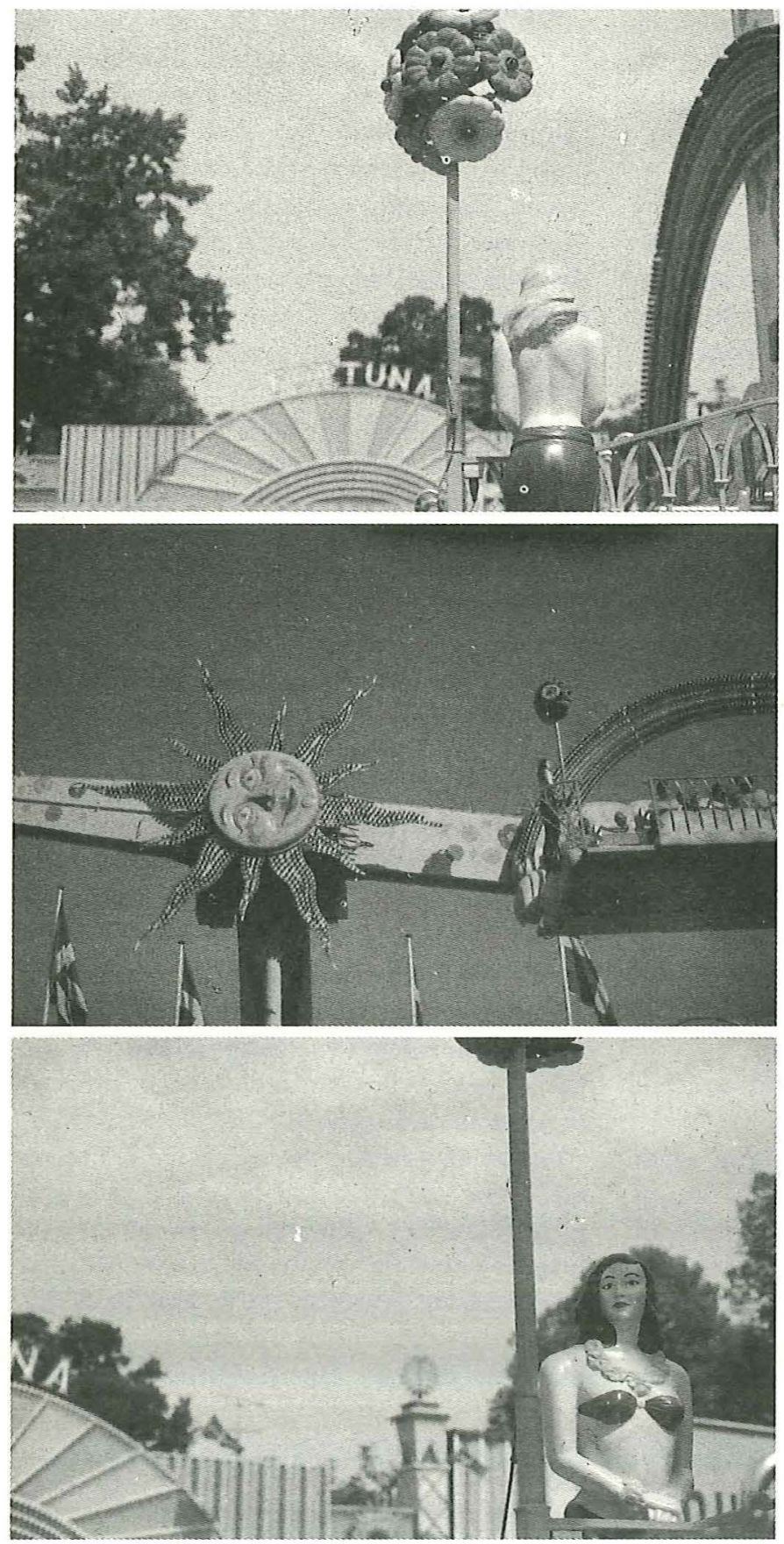
Exhibitions are multi-layered beings. They talk to the unity of the intellect and the emotions, to both the heart and the head, as is sometimes said.

I like to work with movement. I like to compose a fairly tight and lively choreography of the movements of people, but also of objects. At my museum we use revolving stages, conveyor belts and series of speakers and lights to make objects and images float, scoot, twist, run, fade, appear, disappear and reappear and thereby make people turn or bend or almost dance to find or follow them.

This is inviting an even more integrative use of all the senses, breaking both logocentrism and the visual dominance which has become so prevalent in our culture.

We like to use databases and to use high-level technology in audio-visual presentations. We also deal in crude mechanical tricks. We try to make people laugh, so the hushed voices are reserved for the truly awesome displays and not for the idea of a museum. Laugh, so they are free to deal with the serious and heavy stuff we communicate.

Laugh and talk, so that they get to own the place. Breaking the ice, breaking the distance between the museum object, the curator's interpretation and the visitor's perception and reception:-

The overall message transmitted from an exhibition depends on the coupling, relative placing, structuring and sequencing of the individual elements and displays. Getting this context right is an intuitive and artistic affair. But when it is disturbed, the logic and importance become fairly transparent.
Our reconstructed home birth from the 1930 's was structured so that the direction of the room and the woman correlated with the direction of contractions, rippling down through the woman's body. The rhythms and the temporal spacing of the contractions, the continuum of contractions alternating with the breaks, was 'felt' from a tape of a woman's breathing marking contractions, while personal stories of giving birth were told in the pauses.

As a travelling exhibition this woman met another maker. The paradox of giving birth as an essentially private event that most often takes place in the presence of helpers, was invalidated as the woman was turned around, her private parts exposed, and the exhibition structured from the perspective of the spectator. The agent, the subject had changed from the woman giving birth to the - imaginary - doctor. A baby was introduced and extracted by the helper - as it had to be, because neither woman nor baby was alive; a birth was enacted as an instant climax instead of the indefinite suspense and quiet drama of the stories we used. The everyday, miraculous life-and-death event that women deal with was transcribed into a pseudo-event in front of which school children were said to faint.

A similar shift in meta-language happened within our recent exhibition on women inventors, when it was moved to the museum of technology.

We had made extensive use of photographs, documents, drafts and drawings, scribblings and oral histories to emphasise creation as a process as well as the personality of the individual women behind each invention. In this way we portrayed 
106 the extraordinary women who by definition transcend the thinking, but also often the mores of their times, while simultaneously documenting inventions step by step from design to practical implementation or vice versa.

The 2 nd edition of the exhibition lost elements that changed not just the tone of voice, but the totality.

Only isolated three-dimensional objects were shown, no stories, no portraits as contexts, the principle of chronology. was broken.

Gone, again, were the women subjects. Gone was the need to create and invent, the hunches and intuition, the immense will power it takes as well as the equally immense opposing forces that women inventors encounter. Gone was the way inventions tend to be embedded in life as such. Gone was the way that women throughout the century and crossing educational barriers keep a focus on prevention, health, nurturing. Left was a mass of curiosities and a genderless technology, where technological innovation seems either completely accidental or mechanical and linear, one invention so to speak giving birth to the next.

Lost was the dimension of contemporary women inventors stretching, expanding and working radical change within our traditional concepts of technology.

'Invention is about getting access to the unconscious and tapping the knowledge that is already there', as one of the chemical engineers said.

That is also very much what exhibitions are about.

Unearthing the buried knowledge is also what the museum is here for.

\section{NOTES}

1. This paper was given as a lecture on exhibition languages at the Museum Training Institute in 1991. Some things I would probably phrase differently today. A Danish version was printed in the Norwegian Nytt om Kvinneforskning, I, 1994

2. A man told me of recognizing these feelings from sowing the tags onto his father's clothes before taking him to his future nursing home.

3. - which every student of psychology knows represents the mother.

All photos in the article: Lisbeth Nielsen, the Archives of the Women's Museum, Århus Denmark

Jette Sandahl is curator at the Women's Museum in Denmark, of which she is also a founding member. Interested in the relationships between history and character and their three-dimensional re-presentation. Gender is one such relationship and individual interpretation. Member of the Board of the Danish Museum Association. Active within the international networks around women and museums.

Adr: Kvindemuseet, Domkirkepladsen 5, DK-8000 Arhus C, fax +45-86192235 